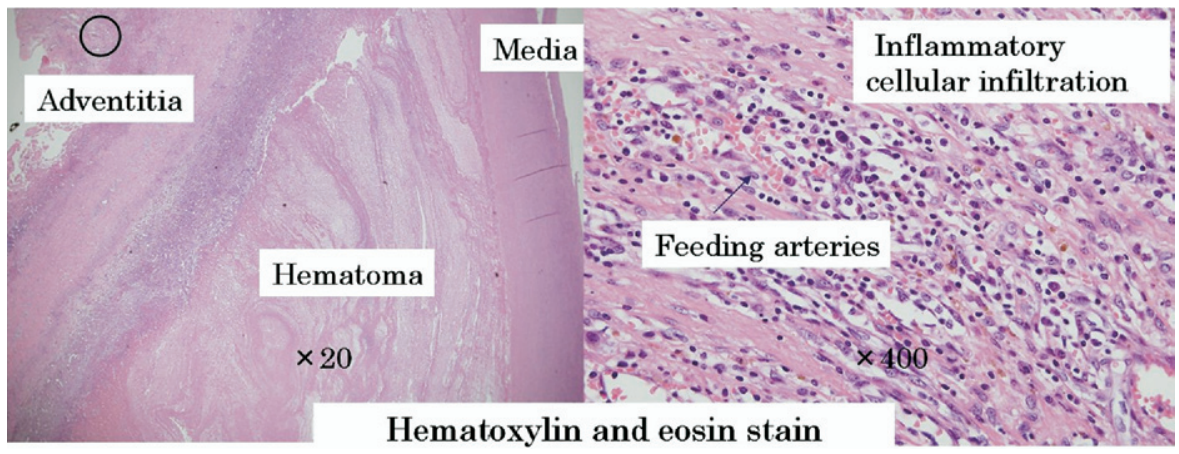

Figure 2. The pathology of the ascending aorta revealed inflammatory cellular infiltration of lymph corpuscle and plasma cells in adventitia.

caused by the rupture of vasa vasorum of fragile media after syphilitic aortitis and by cicatrized intima and adventitia.

\section{References}

1. Heggtveit HA. Syphilitic aortitis. Circulation. 1964;29;346-55.

2. Svesson LG, Crawford ES. Cardiovascular and vascular disease of the aorta. Philadelphia: W.B. Saunders; 1997.
3. Tai YT, Mok CK, Chow WH, Chan FL, So KF. Ascending aortic dissection complicating syphilitic aortitis, late after aortic valve replacement. Clin Cardiol. 1990;13:227-9.

4. Kallett MW, Young GR, Fletcher NA. Paraparesis due to syphilitic aortic dissection. Neurology. 1997;48:221-3.

5. Chauvel C, Cohen A, Albo C, Ziol M, Valty J. Aortic dissection and cardiovascular syphilis: report of an observation with transesophageal echocardiography and anatomopathologic findings. J Am Soc Echocardiogr. 1994;7:419-21

\title{
Purse-string deformity of the right coronary artery: A pitfall in de Vega tricuspid annuloplasty
}

Petr Symersky, MD, ${ }^{a}$ Anton P. de Jong, MD, PhD, ${ }^{a}$ Karel T. Koch, MD, PhD, ${ }^{b}$ Edouard M. de Beaumont, MD, ${ }^{c}$ and Bas A. J. M. de Mol, MD, PhD, ${ }^{\text {a }}$ Amsterdam, The Netherlands

I njury to the right coronary artery (RCA) is a rare complication of tricuspid annuloplasty. Because of its course in the right atrioventricular groove, the RCA is vulnerable to direct mechanical injury. ${ }^{1}$ However, we present a case in which a de Vega annuloplasty caused excessive deformation of the RCA and resulted in an acute coronary syndrome.

\section{Clinical Summary}

A 64-year-old woman was referred for mitral and tricuspid annuloplasty. She had undergone mechanical aortic valve replacement

From the Departments of Cardiothoracic Surgery, ${ }^{\mathrm{a}}$ Cardiology, ${ }^{\mathrm{b}}$ and Anesthesiology, ${ }^{\mathrm{c}}$ Academic Medical Center, Amsterdam, The Netherlands.

Received for publication Nov 23, 2006; accepted for publication Dec 7, 2006.

Address for reprints: Bas A. J. M. de Mol, MD, PhD, Department of Cardiothoracic Surgery, Room G4-209, Academic Medical Center Amsterdam, PO Box 22700, 1100 DE Amsterdam, The Netherlands (E-mail: b.a.demol@amc.uva.nl).

J Thorac Cardiovasc Surg 2007;133:1086-7

$0022-5223 / \$ 32.00$

Copyright $\odot 2007$ by The American Association for Thoracic Surgery doi:10.1016/j.jtcvs.2006.12.025 because of acute endocarditis 14 years before. Subsequently she had been followed for mitral insufficiency and presented recently with dyspnea. There was severe mitral insufficiency caused by systolic restrictive motion of the posterior mitral leaflet (Carpentier $3 \mathrm{~b})$ with a dilated left ventricle and severely impaired systolic function. A concomitant tricuspid insufficiency was found with an annulus diameter of $42 \mathrm{~mm}\left(25 \mathrm{~mm} / \mathrm{m}^{2}\right)$, a dilated right ventricle, and good systolic function. There was no coronary artery disease.

Restrictive mitral annuloplasty was performed with placement of a 30-mm ring (Edwards Lifesciences, Irvine, Calif). A de Vega tricuspid annuloplasty was performed. A control transesophageal echocardiogram showed mild residual mitral insufficiency and no tricuspid insufficiency or stenosis (annulus diameter $22 \mathrm{~mm}, 13$ $\mathrm{mm} / \mathrm{m}^{2}$ ). The course of the operation was uneventful until closure of the chest when ST elevations appeared in the inferior leads. A transesophageal echocardiogram showed a worsening of the wall motion abnormalities of the posterior and inferior left ventricular wall. Reinspection showed no exterior compression of the $\mathrm{RCA}$, and the patient was subsequently presented for coronary angiography.

In contrast with the preoperative angiography, there was marked kinking of the proximal RCA followed by an occlusion of the third segment (Figure 1). This site showed sharp angulation that was not visible on the preoperative angiogram and was sug- 


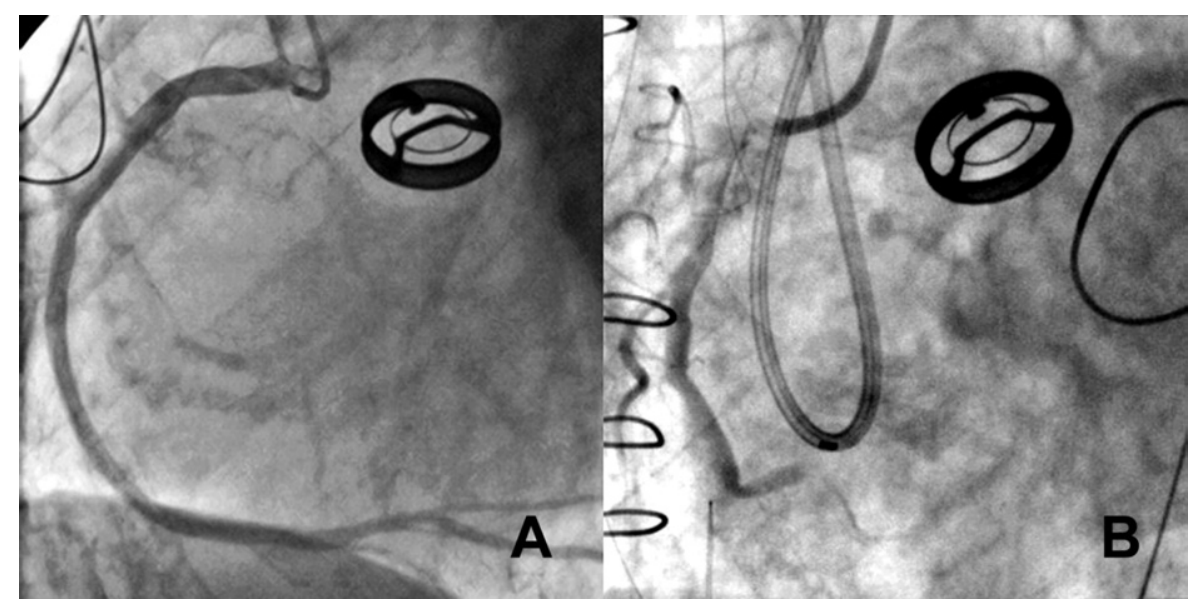

Figure 1. Coronary angiogram of the RCA preoperatively (A) and at presentation postoperatively (B). RCA, right coronary artery.

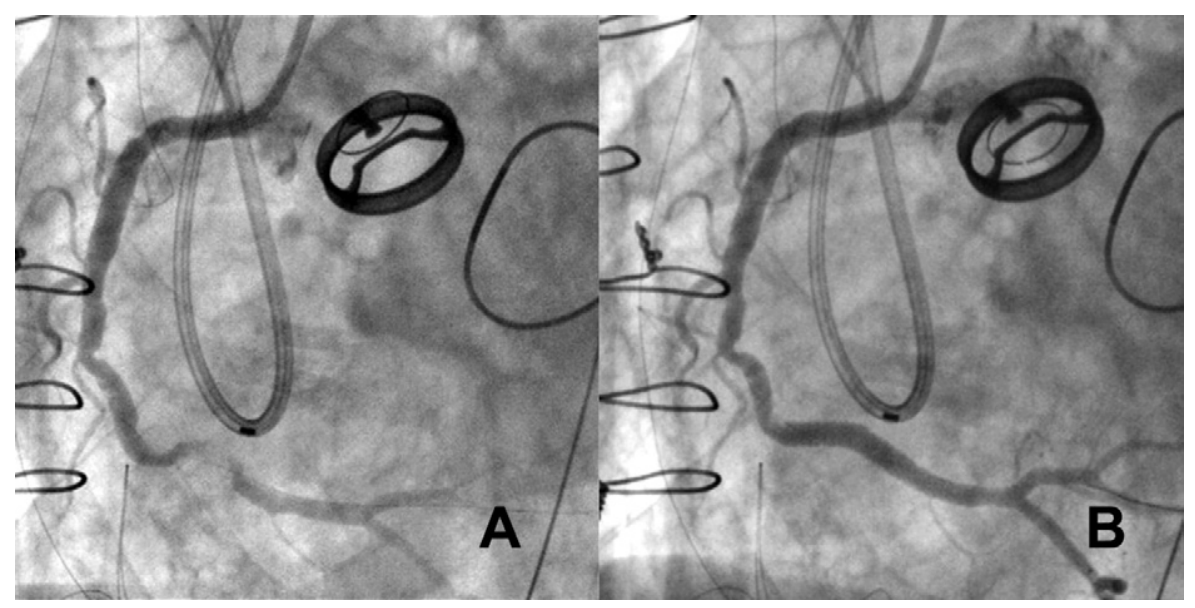

Figure 2. Angiogram of the RCA after wire passage (A) and stenting (B). RCA, right coronary artery.

gestive of mechanical retraction. It took some effort to cross the lesion with a 0.014 -inch percutaneous coronary intervention wire. Because thrombotic occlusion of an originally normal vessel had to be anticipated, an aspiration catheter was introduced but could not be advanced past the occlusion (Figure 2, A). No material was aspirated. A percutaneous coronary intervention balloon could be advanced easily and adequately deployed, which made a ligation by a suture unlikely. The occlusion appeared to be the result of mechanical deformation, and it was decided to stent the invaginated segment. Two stents could be inserted, only passing the tortuous anatomy with the assist of an additional supportive guidewire. With adequate restoration of flow, the milder proximal lesions caused by mechanical deformation were not addressed (Figure 2,B). An intraaortic balloon pump was inserted for stabilization.

Although there was biochemical evidence for sizeable myocardial damage, the patient remained stable and was detubated after 20 hours. She was transferred to the referring hospital 12 days postoperatively.

\section{Discussion}

This case illustrates the limits of restrictive de Vega annuloplasty. Although it is widely accepted and practiced, few reports have focused on the complications. The proximity of the RCA to the tricuspid annulus makes it vulnerable to direct injury. ${ }^{1}$ A de Vega annuloplasty with a reduction of the annular diameter from 42 to $22 \mathrm{~mm}$ caused a seemingly pristine RCA to invaginate and kink in our patient. The mechanism of the deformation may be a combination of traction from individual suture bites and a marked reduction of the atrioventricular circumference. The angiographic findings make direct injury or thrombotic occlusion highly unlikely. Furthermore, the extensive deformation of the proximal RCA demonstrates that the RCA is more affected by restrictive tricuspid annuloplasty than is routinely evident.

\section{Reference}

1. Rubens FD, Bedard P, Walley VM. Right coronary artery injury during tricuspid valve annuloplasty. J Cardiovasc Surg (Torino). 1990;31:533-5. 